\title{
$\mathbb{A}$ Economics Bulletin
}

Volume 37, Issue 2

\section{An argument against Cobb-Douglas production functions (in multi-sector growth modeling)}

\author{
Denis Stijepic \\ University of Hagen
}

\begin{abstract}
Recent growth literature deals with long run cross-sector labor allocation dynamics in multi-sector growth models. We analyze what the adequate assumptions regarding the sectoral production functions in this type of (very long run) model are. By employing an axiomatic/geometrical approach, we demonstrate that the basic stylized facts of long run sector and aggregate dynamics and the standard theory axioms are not consistent with the assumption of CobbDouglas production functions at the sector level. This result can be regarded as an empirical rejection of the CobbDouglas production function (at the sector level) on the basis of very long run, qualitative data.
\end{abstract}

I thank the anonymous referees, Damir Stijepic, and Katrin Heinrichs for valuable comments.

Citation: Denis Stijepic, (2017) "An argument against Cobb-Douglas production functions (in multi-sector growth modeling)", Economics Bulletin, Volume 37, Issue 2, pages 1143-1150

Contact: Denis Stijepic - denis.stijepic@fernuni-hagen.de.

Submitted: February 06, 2017. Published: May 25, 2017. 


\section{Introduction}

We analyze whether the Cobb-Douglas production function (henceforth "CDPF") is suitable for modeling production at the sector level in very long run multi-sector growth models. This question is not only relevant to the general growth theory (see, e.g., the references in Section 2 ), but also to the growing branch of multi-sector growth modeling that relies on assumptions regarding sectoral production functions for modeling cross-sector labor reallocation over very long periods of time (for an overview see, e.g., Muro 2013, and Herrendorf et al. 2014).

Our approach of analysis allows us to assess the validity of CDPFs by employing qualitative information on very long periods of time. We collect some widely accepted stylized facts regarding (the long run dynamics of) the agricultural, manufacturing and services sector (and aggregates). Furthermore, we assume the validity of standard axioms/assumptions of long run multi-sector modeling. We demonstrate that these stylized facts and theory axioms are not consistent with the assumption of CDPFs at the sector level. This fact implies that CDPFs are not adequate for modeling sector-level production in theories of long run agriculturemanufacturing-services dynamics (satisfying the standard axioms). Furthermore, our results support the view that changing elasticity of factor substitution at the sector level may be a significant determinant of sector level dynamics (cf. Alvarez-Cuadrado et al. 2015). ${ }^{1}$

\section{On the Constancy of the Aggregate Labor Income Share (W)}

For a literature overview regarding the CDPF, see, e.g., Chirinko (2008) and AlvarezCuadrado et al. (2015). As discussed by Gollin (2002), a central part of the CDPF discussion is about the fact that the CDPF implies that the aggregate labor income share (W) is constant: the evidence regarding the constancy of $\mathrm{W}$ is mixed; nevertheless, the proponents of "Kaldorfacts" adhere to the view that W can be regarded as "constant" (at least in theoretical long run models). ${ }^{2}$ To encompass this dispute, we assume in all our derivations that $\mathrm{W}$ is constant in the long run (cf. Proposition 2). Our results imply that, nevertheless, CDPFs must be rejected (at the sector level).

As discussed in Section 4, the structural change process can be divided into two phases (cf. Stylized Fact 3): the initial industrialization phase, which is characterized by a growing employment share of manufacturing, and a subsequent tertiarization phase, which is characterized by a decreasing manufacturing share. For example, the data depicted in Figure 1 shows that (a) in the USA, the process of industrialization continued until the 1960s and (b) from then on, the USA went through a phase of tertiarization.

Since the existence of the two structural change phases (cf. Stylized Fact 3) and the constancy of W (cf. Proposition 2) are essential parts of our argumentation, it makes sense to discuss briefly the empirical evidence on the constancy of $\mathrm{W}$ over the two structural change phases. Fortunately, for providing evidence on the constancy of W (in the long run), the proponents of Kaldor-facts rely on data that covers parts of both structural change phases (see, e.g., the pioneering contribution by Kongsamut et al. 2001). In particular, the authors who provide empirical evidence on the constancy of $\mathrm{W}$ in the USA rely on data that covers both, a part of

\footnotetext{
${ }^{1}$ Alvarez-Cuadrado et al. (2015) focus on a two-sector framework (manufacturing-services), study a relatively short period of time (ca. 50 years) and focus on quantitative analysis. We study the qualitative dynamics of the agriculture-manufacturing-services-framework over very long periods of time (200 years).

${ }^{2}$ For (discussion of) the evidence regarding the constancy of W, see, e.g., King and Rebello (1999), p.941, Gollin (2002), p.460, Barro and Sala-i-Martin (2004), p.12, and Acemoglu (2009), p.57. Furthermore, note that a great part of the recent multi-sector growth modeling literature (see, e.g., Herrendorf et al. 2014 for an overview) focuses on structural change paths that are characterized by a constant aggregate labor income share.
} 
the pre-1960s period and a part of the post-1960s period. For example, King and Rebello (1999), p.941, rely on US data covering the period 1947-1997, Gollin (2002), p.460, refers to the period 1935-1985, Acemoglu (2009), p.57, relies on 1929-1999 US data, and Barro and Sala-i-Martin (2004), p.12, discuss several studies on the constancy of W in the USA relying on data covering a part of the pre-1960s period and a part of the post-1960s period.

Figure 1. Sectoral employment shares (\%) in the USA (1870-1984).

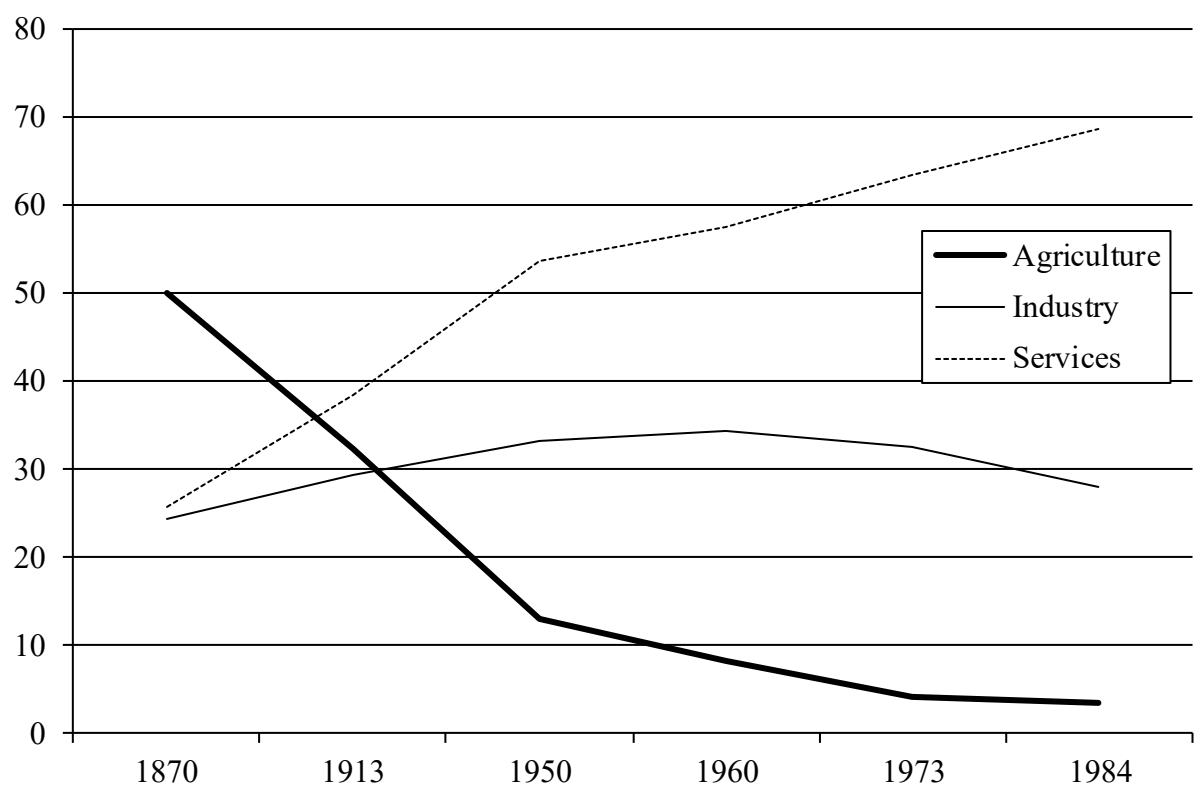

Data source: Maddison (1995), p.76.

\section{Geometrical Properties of Structural Change Models}

Let $\mathrm{L}_{\mathrm{a}}, \mathrm{L}_{\mathrm{m}}$ and $\mathrm{L}_{\mathrm{s}}$ denote the share of employment devoted to agriculture, manufacturing and services, respectively. Axiom 1 represents the typical assumptions in structural change modeling (see also Stijepic 2015a).

Axiom 1. The labor allocation $\left(L_{a}, L_{m}, L_{s}\right)$ satisfies the following conditions:

$L_{a}+L_{m}+L_{s}=1$

$L_{i} \geq 0$ for $i=a, m, s$

Let $\Delta_{2}$ denote the set of all the points $\left(\mathrm{L}_{\mathrm{a}}, \mathrm{L}_{\mathrm{m}}, \mathrm{L}_{\mathrm{s}}\right)$ that satisfy conditions (1)-(2), i.e.,

$\Delta_{2}:=\left\{\left(\mathrm{L}_{\mathrm{a}}, \mathrm{L}_{\mathrm{m}}, \mathrm{L}_{\mathrm{s}}\right) \in \mathbf{R}^{3}: \mathrm{L}_{\mathrm{a}} \geq 0, \mathrm{~L}_{\mathrm{m}} \geq 0, \mathrm{~L}_{\mathrm{s}} \geq 0, \mathrm{~L}_{\mathrm{a}}+\mathrm{L}_{\mathrm{m}}+\mathrm{L}_{\mathrm{s}}=1\right\}$

It is well known that $\Delta_{2}$ is a triangle (or 2-simplex) with the following coordinates of its vertices (which we name $A, M$ and $S$ ) in the Cartesian coordinate system $\left(L_{a}, L_{m}, L_{s}\right)$ : $(1,0,0):=A,(0,1,0):=M$ and $(0,0,1):=S$ (cf. Stijepic 2015a). See Figure 2. 
Figure 2. $\Delta_{2}$ in the Cartesian coordinate system $\left(L_{a}, L_{m}, L_{s}\right)$.

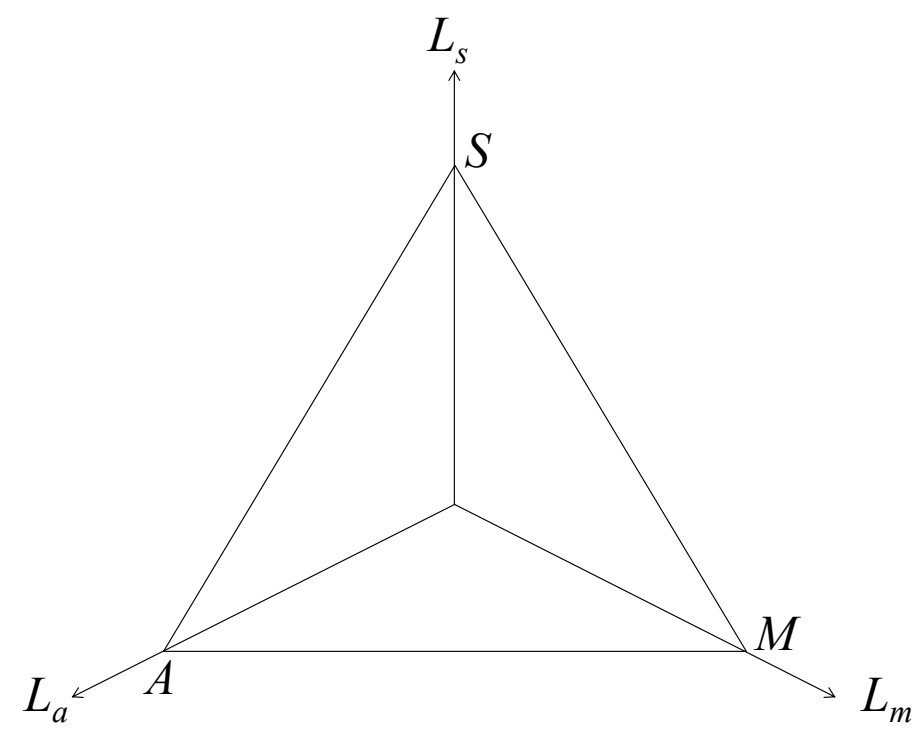

Overall, any labor allocation satisfying Axiom 1 can be represented by a point on the 2simplex in Figure 2. Changes in the labor allocation (i.e., structural changes) can be visualized as a movement (of a point) along the 2 -simplex. That is, we can visualize structural change as a path (or: trajectory) on the 2-simplex; see Figure 3 for an example (where we omitted the coordinate axes).

Figure 3. A structural change trajectory on the 2-simplex.

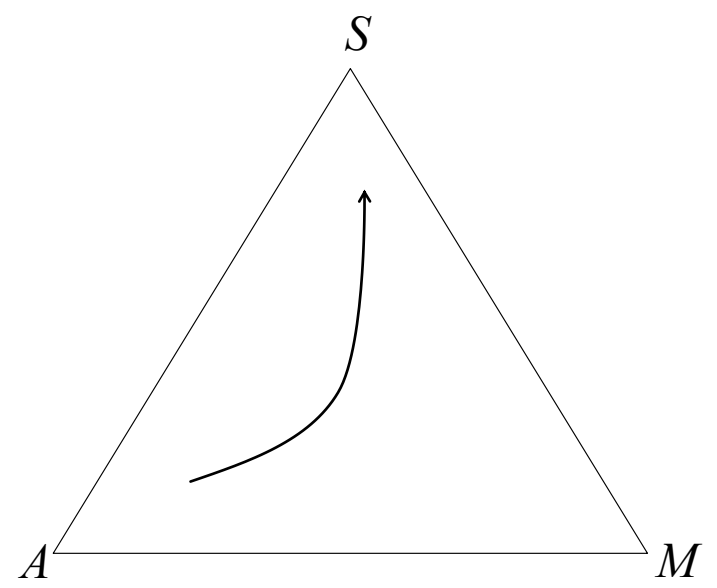

\section{Stylized Facts and their Geometrical Interpretation}

The following three stylized facts, which refer to very long periods of time (e.g. 100 to 200 years) are well known in the literature; see, e.g., Stijepic (2015a) for discussion and references. 
Stylized Fact 1. The employment share of agriculture $\left(L_{a}\right)$ declines (monotonously) over the development process.

Stylized Fact 2. The employment share of services $\left(L_{s}\right)$ increases (monotonously) over the development process.

Stylized Fact 3. The dynamics of the manufacturing share $\left(L_{m}\right)$ are non-monotonous over the development process: initially (over the industrialization phase) the manufacturing share increases (with time), while later (over the "tertiarization" phase) the manufacturing share declines (with time).

The existence of cross-sector technology differences seems obvious and is well known in the literature; see, e.g., Baumol (1967), Ngai and Pissarides (2007), Acemoglu and Guerrieri (2008), and Muro (2013) for modeling of such technology differences. For evidence, see, e.g., Solow (1958), p.623, Close and Shulenburger (1971), p.592, Gollin (2002), p.464, Acemoglu and Guerrieri (2008), p.486, Valentinyi and Herrendorf (2008), and AlvarezCuadrado et al. (2015). This literature is reflected by the following stylized fact.

Stylized Fact 4. Technology differs across sectors. In particular, capital intensity and labor income share differ across sectors.

It is well known that the exponents of the CDPF are closely related to the labor income share and to the (optimal) capital intensity (see, e.g., Acemoglu and Guerrieri 2008). In Section 5, we use this fact to translate Stylized Fact 4 into Axiom 5.

Proposition 1. Assume an economy that satisfies Stylized Facts 1-3. Furthermore, let this economy be in the phase of tertiarization at time $t_{T}$. The trajectory describing the (past) structural change dynamics of this economy for $t<t_{T}$ is non-linear on $\Delta_{2}$, as depicted in Figure 3.

Proof. Stylized Facts 1 and 2 imply that over the development process, the economy moves on $\Delta_{2}$ monotonously towards vertex $\mathrm{S}$; cf. Section 3 . Figure 2 implies that, if an economy moves (monotonously) along a linear trajectory on $\Delta_{2}$ (towards vertex $\mathrm{S}$ ), one and only one of the following statements is true: (S1) the employment share of manufacturing increases strictly monotonously along the trajectory; (S2) the employment share of manufacturing decreases strictly monotonously along the trajectory; (S3) the manufacturing share is constant along the trajectory. We can see that none of these three cases is consistent with Stylized Fact 3. Thus, the economy satisfying Stylized Fact 3 cannot be described by a linear trajectory.

See also Stijepic (2015a), p.83f., for a more intuitive discussion of Proposition 1. 


\section{Theoretical Axioms and their Geometrical Interpretation}

Axioms 2 and 3 are typical for (multi-sector) long run growth models, e.g., Baumol (1967), Kongsamut et al. (2001), Ngai and Pissarides (2007), Acemoglu and Guerrieri (2008), and Foellmi and Zweimuller (2008).

Axiom 2. There is perfect labor mobility across sectors. In particular, the wage rate $w_{i}$ is equal across all sectors $i$, i.e., $w_{i}=w \forall i$.

Axiom 3. The wage rate in sector $i$ is equal to the marginal productivity of labor in sector $i$, i.e., $w_{i}=p_{i} \partial Y_{i} /\left(\partial\left(L_{i} \Lambda\right)\right) \forall i$, where $p_{i}$ is the price of sector-i-output, $Y_{i}$ is the output in sector $i$, and $\Lambda$ is the aggregate employment.

The following axiom introduces the Cobb-Douglas production function.

Axiom 4. The sectoral production functions are of type Cobb-Douglas with labor as an input factor and an arbitrary number (n) of further input factors (e.g. capital and human capital), i.e., $Y_{i}=\left(L_{i} \Lambda \Gamma_{i L}\right)^{\alpha_{i}} \prod_{j=1}^{n}\left(\Gamma_{i j} x_{i j}\right)^{\beta_{i j}}$, where: $x_{i j}$ stands for the input of factor $j$ in sector $i$; $\Gamma_{i L}$ and $\Gamma_{i j}$ are productivity parameters; $i=a, m, s ;$ and $j=1,2, \ldots, n$.

Since the parameters/variables $\Gamma_{\mathrm{iL}}, \Gamma_{\mathrm{ij}}, \Lambda$ and $\mathrm{x}_{\mathrm{ij}}$ do not enter the equations used to prove Proposition 2 (cf. (1), (2) and (4)), we do not need to make any restricting assumptions about their growth rates. That is, our results are consistent with the assumption that (a) the productivity parameters $\left(\Gamma_{\mathrm{iL}}\right.$ and $\left.\Gamma_{\mathrm{ij}}\right)$ grow at arbitrary and sector-specific rates (thus, reflecting cross-sector differences in productivity growth), (b) the aggregate employment $(\Lambda)$ grows at an arbitrary rate and (c) input factors $\mathrm{x}_{\mathrm{ij}}$ are accumulated at arbitrary and sectorspecific rates.

Axiom 5 introduces the cross-sector technology differences postulated in Stylized Fact 4.

Axiom 5. $\exists i \in\{a, m, s\}: \alpha_{i} \neq \alpha_{j}$, where $i \neq j$ and $j \in\{a, m, s\}$.

We define the (aggregate) labor income share as the ratio between the wage (sum) and the (aggregate) income:

Definition 1. The aggregate labor income share is given by $\left(w_{a} L_{a} \Lambda+w_{m} L_{m} \Lambda+w_{s} L_{s} \Lambda\right) /\left(p_{a} Y_{a}+\right.$ $\left.p_{m} Y_{m}+p_{s} Y_{s}\right)=: W$.

In general, it is assumed that the sum of the exponents of the Cobb-Douglas function is equal to one, i.e., $\alpha_{i}+\sum_{j=1}^{n} \beta_{i j}=1 \forall i, \alpha_{i} \geq 0 \forall i, \beta_{i j} \geq 0 \forall i \forall j$. 
Proposition 2. Assume that Axioms 1-5 are satisfied. Furthermore, assume that the aggregate labor income share $(\boldsymbol{W})$ is constant (cf. Definition 1). Under these conditions, the trajectory describing the dynamics of the labor-allocation $\left(L_{a}, L_{m}, L_{s}\right)$ on $\Delta_{2}$ is linear, i.e., the economy moves along a line segment on $\Delta_{2}$.

Proof. Axiom 4 implies: $\partial \mathrm{Y}_{\mathrm{i}} /\left(\partial\left(\mathrm{L}_{\mathrm{i}} \Lambda\right)\right)=\alpha_{\mathrm{i}} \mathrm{Y}_{\mathrm{i}} /\left(\mathrm{L}_{\mathrm{i}} \Lambda\right) \forall \mathrm{i}$. Thus, $\mathrm{p}_{\mathrm{i}} \mathrm{Y}_{\mathrm{i}}=\mathrm{L}_{\mathrm{i}} \Lambda \mathrm{w}_{\mathrm{i}} / \alpha_{\mathrm{i}} \forall \mathrm{i}$; cf. Axiom 3. Thus, $\mathrm{W}=\left(\mathrm{w}_{\mathrm{a}} \mathrm{L}_{\mathrm{a}}+\mathrm{w}_{\mathrm{m}} \mathrm{L}_{\mathrm{m}}+\mathrm{w}_{\mathrm{s}} \mathrm{L}_{\mathrm{s}}\right) /\left(\mathrm{w}_{\mathrm{a}} \mathrm{L}_{\mathrm{a}} / \alpha_{\mathrm{a}}+\mathrm{w}_{\mathrm{m}} \mathrm{L}_{\mathrm{m}} / \alpha_{\mathrm{m}}+\mathrm{w}_{\mathrm{s}} \mathrm{L}_{\mathrm{s}} / \alpha_{\mathrm{s}}\right)$; cf. Definition 1. Thus, $\mathrm{W}=$ $\left(\mathrm{L}_{\mathrm{a}}+\mathrm{L}_{\mathrm{m}}+\mathrm{L}_{\mathrm{s}}\right) /\left(\mathrm{L}_{\mathrm{a}} / \alpha_{\mathrm{a}}+\mathrm{L}_{\mathrm{m}} / \alpha_{\mathrm{m}}+\mathrm{L}_{\mathrm{s}} / \alpha_{\mathrm{s}}\right)$; cf. Axiom 2. Thus, $\mathrm{W}=1 /\left(\mathrm{L}_{\mathrm{a}} / \alpha_{\mathrm{a}}+\mathrm{L}_{\mathrm{m}} / \alpha_{\mathrm{m}}+\mathrm{L}_{\mathrm{s}} / \alpha_{\mathrm{s}}\right)$; cf. (1) (Axiom 1). This equation and the fact that $\mathrm{W}$ is constant (cf. Proposition 2) imply:

$\mathrm{L}_{\mathrm{a}} / \alpha_{\mathrm{a}}+\mathrm{L}_{\mathrm{m}} / \alpha_{\mathrm{m}}+\mathrm{L}_{\mathrm{s}} / \alpha_{\mathrm{s}} \equiv \mathrm{c}=$ const.

The basic knowledge of vector algebra (and geometry) implies that (1), (2) and (4) (and Axiom 5) determine a line segment on $\Delta_{2}$, as explained in the following. See also Figure 4. (1) and (2) span a standard 2-simplex $\left(\Delta_{2}\right)$ in the three-dimensional Cartesian coordinate system $\left(\mathrm{L}_{\mathrm{a}}, \mathrm{L}_{\mathrm{m}}, \mathrm{L}_{\mathrm{s}}\right)$, as shown in Section 3; (4) spans a plane in this coordinate system. Thus, the set of points that satisfy (1), (2), and (4) is given by the intersection of $\Delta_{2}$ and the plane (4). We know that this intersection is a line segment (and not the whole area of $\Delta_{2}$ ) because Axiom 5 implies that plane (1), which contains $\Delta_{2}$, and plane (4) do not overlap completely, i.e., plane (1) and plane (4) are not identical: Axiom 5 ensures that the equation $\alpha_{\mathrm{a}} \mathrm{c}=\alpha_{\mathrm{m}} \mathrm{c}=$ $\alpha_{\mathrm{s}} \mathrm{c}$ is never satisfied; thus, (4) and (1) never define one and the same set in the Cartesian coordinate system $\left(\mathrm{L}_{\mathrm{a}}, \mathrm{L}_{\mathrm{m}}, \mathrm{L}_{\mathrm{s}}\right)$.

Overall, these facts imply that the set of all allocations $\left(\mathrm{L}_{\mathrm{a}}, \mathrm{L}_{\mathrm{m}}, \mathrm{L}_{\mathrm{s}}\right)$ that satisfy Axioms 1-5 and condition "W = const." (cf. Definition 1) is represented by a line segment on $\Delta_{2}$. Thus, the structural change trajectory of an economy satisfying "W = const." (cf. Definition 1) and Axioms 1-5 must be linear.

Figure 4. An example of the intersection (line segment P1-P2) between $\Delta_{2}$ (triangle AMS) and plane (4).

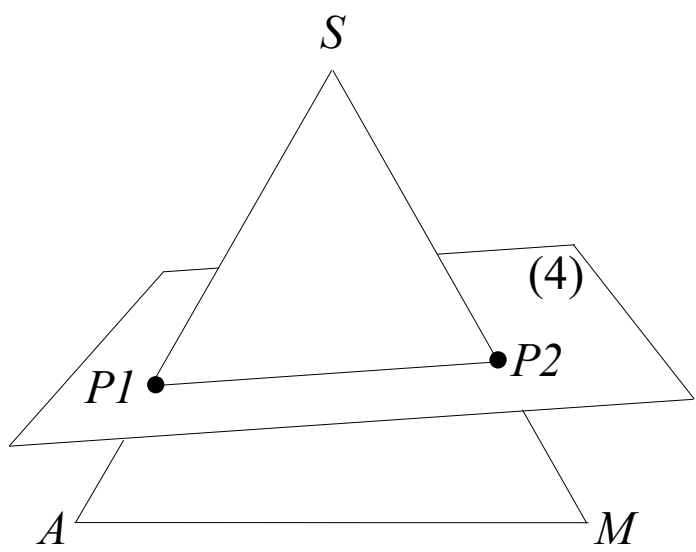




\section{Conclusion}

Proposition 1 states that the stylized facts (of structural change) imply a non-linear trajectory of structural change. Proposition 2 states that the standard theory axioms with Cobb-Douglas production functions at the sector level imply a linear trajectory of structural change if we assume that the aggregate labor income share (W) is constant (cf. Section 2). Thus, the contradiction between Propositions 1 and 2 (non-linear vs. linear trajectory) implies that the stylized facts and the standard theory axioms with Cobb-Douglas production functions (and "W = const.") are incompatible. This implies among others that any standard multi-sector growth model (i.e. any multi-sector model that satisfies Axioms 2 and 3) cannot be consistent with the most basic stylized facts ("W = const.", Stylized Facts 1-3 and Stylized Fact 4/Axiom 5), if it assumes CDPFs at the sector level (Axiom 4).

Overall, the (logical) contradiction between Propositions 1 and 2 implies that CDPFs are not adequate for modeling sector-level production in the theories of long run agriculturemanufacturing-services dynamics satisfying Axioms 2 and 3.

\section{References}

Acemoglu, D. (2009) Introduction to Modern Economic Growth, Princeton University Press: Princeton, N.J.

Acemoglu, D. and V. Guerrieri (2008) "Capital deepening and non-balanced economic growth" Journal of Political Economy 116, 467-498.

Alvarez-Cuadrado, F., Long, N.V., and M. Poschke (2015) "Capital-labor substitution, structural change and the labor income share" IZA discussion paper number 8941.

Barro, R.J. and X. Sala-i-Martin (2004) Economic Growth, 2nd edition, MIT Press: Cambridge, Mass.

Baumol, W.J. (1967) "Macroeconomics of unbalanced growth: the anatomy of urban crisis" American Economic Review 57, 415-426.

Chirinko, R.S. (2008) “ $\sigma$ : the long and short of it” CESifo working paper number 2234.

Close, F.A. and D.E. Shulenburger (1971) "Labor's share by sector and industry, 1948-1965" Industrial and Labor Relations Review 24, 588-602.

Foellmi, R. and J. Zweimueller (2008) "Structural change, Engel's consumption cycles and Kaldor's facts of economic growth" Journal of Monetary Economics 55, 1317-1328.

Gollin, D. (2002) “Getting income shares right” Journal of Political Economy 110, 458-474.

Herrendorf, B., Rogerson, R., and Á. Valentinyi (2014) "Growth and structural transformation" in Handbook of Economic Growth (Volume 2B) by P. Aghion and S.N. Durlauf, Eds., Elsevier B.V.

King, R.G. and S.T. Rebelo (1999) "Resuscitating real business cycles" in Handbook of Macroeconomics (Volume 1) by J.B. Taylor and M. Woodford, Eds., Elsevier B.V.

Kongsamut, P., Rebelo, S., and D. Xie (2001) "Beyond balanced growth" Review of Economic Studies 68, 869-882.

Maddison, A. (1995) Explaining the Economic Performance of Nations - Essays in Time and Space, Edward Elgar Publishing, Cambridge University Press. 
Muro, K. (2013) "A note on the three-sector Cobb-Douglas GDP function" Economic Modelling 31, 18-21.

Ngai, R.L. and C.A. Pissarides (2007) "Structural change in a multisector model of growth" American Economic Review 97, 429-443.

Solow, R.M. (1958) "A skeptical note on the constancy of relative shares" The American Economic Review 48, 618-631.

Stijepic, D. (2015a) “A geometrical approach to structural change modeling" Structural Change and Economic Dynamics 33, 71-85.

Stijepic, D. (2015b) “An argument against Cobb-Douglas production functions (in multisector-growth modeling)" available at SSRN: http://ssrn.com/abstract=2610734 or http://dx.doi.org/10.2139/ssrn.2610734

Valentinyi, A. and B. Herrendorf (2008) "Measuring factor income shares at the sectoral level" Review of Economic Dynamics 11, 820-835. 